\title{
Hydrodynamic process of Tibetan Plateau lake revealed by grain size: Case study of Pumayum Co
}

\author{
JU JianTing $^{1 *}$, ZHU LiPing ${ }^{1}$, FENG JinLiang ${ }^{1}$, WANG JunBo ${ }^{1}$, WANG Yong ${ }^{1}$, XIE ManPing ${ }^{2}$, \\ PENG Ping ${ }^{1}$, ZHEN XiaoLin $^{1} \&$ LÜ XinMiao ${ }^{1}$ \\ ${ }^{1}$ Key Laboratory of Tibetan Environment Changes and Land Surface Processes, Institute of Tibetan Plateau Research, Chinese Academy of \\ Sciences, Beijing 100101, China; \\ ${ }^{2}$ College of Tourism and Geography Sciences, Yunan Normal University, Kunming 650500, China
}

Received January 2, 2012; accepted February 6, 2012; published online April 12, 2012

\begin{abstract}
Under the background of global warming, some lakes on the Tibetan Plateau (TP) are potentially sensitive to temperature change. With a case study of Pumayum Co, where glacier meltwater is important to supply (we call this a glacier-fed lake hereafter), we analyze the sensitivity of lake sediment grain size to temperature change. This is done by resolving the modern hydrodynamic process, coupled with comparison of paleoclimatic proxies. According to the spatial distributions of parameters, percentage of grain size and the grain size frequency distribution curve, hydrodynamic processes are analyzed. Five clastic sedimentation types are thereby discriminated. In the open lake area, suspended load transport is the main transport agent. Grain Size Trend Analysis (GSTA), a sediment dynamics model, reveals a trend toward eastward transport. This indicates that the largest and glacier-fed river, the Jiaqu River, influences the entire lake (not just the subsurface alluvial fan), and that lake sediment grain size may serve as a temperature indicator. Time series comparison between grain size of a short core from the central lake and meteorological data confirms this temperature indication, which in turn shows reliability of the method discriminating the hydrodynamic process. This case study will improve the ability of paleoclimatic reconstruction using lake sediment in glacier-fed lakes on the Tibetan Plateau.
\end{abstract}

grain size, environmental significance, Pumayum Co, hydrodynamic process, grain size trend analysis

Citation: Ju J T, Zhu L P, Feng J L, et al. Hydrodynamic process of Tibetan Plateau lake revealed by grain size: Case study of Pumayum Co. Chin Sci Bull, 2012, 57: 2433-2441, doi: 10.1007/s11434-012-5083-5

Glaciers and lakes are sensitive indicators of climatic change. Under the background of global warming, modern environmental change on the Tibetan Plateau has become a global focus topic [1]. Observed data from meteorological stations [2] and glacier cores [3-6] indicate that temperature increase has accelerated since the 20th century, and is more obvious at higher altitudes. With the temperature rise, lakes near glaciers are noticeably expanding; this includes most lakes on the central TP [7-9] and Nam Co (in Tibetan, co means lake) $[10,11]$. The dominant cause for this is the increase of glacier meltwater from the temperature rise $[8,9,11,12]$. Therefore, glacier-fed lakes are potentially sen-

*Corresponding author (email: Jujianting@itpcas.ac.cn) sitive to temperature change.

Lake sediments have great significance in climatic and environmental reconstruction of the late Quaternary. The grain-size distribution of lake sediments has long been used as a proxy for lake hydrologic conditions associated with regional climatic and environmental changes, because of its sensitivity to hydrodynamic history and inexpensive measurement. It is widely accepted that coarser sediments indicate a lower lake level and drier climate, and finer sediments a higher lake level and wetter climate. However, other studies found a positive relation between grain size and precipitation [13-16]. In a glacier-fed lake, grain size may indicate temperature indirectly. For example, in Chen Co of South Tibet, the change of grain size is contrary to summer 
temperature. It has been suggested that grain size may indicate lake level change, which is subject to the amount of glacier meltwater controlled by temperature $[17,18]$. In other Tibetan lakes such as Pumayum Co, three periods of larger grain size may correspond to a warm and wet TP environment [19]. In Nam Co, coarser sediments from 7 cal ka BP may indicate inflow increase [20]. In Lake Cuoe, coarser sediments may indicate inflow increase caused by precipitation increase [21]. From the above results, the environmental significance has multiple solutions. To clarify such complicated relations, the main method of the paleolimnologist is to compare different proxies of time series or at best, proxies and observed data [13,17,22]. Direct evidence from the modern sedimentary process is insufficient [23], resulting in uncertain explanation of results [24]. Especially in middle-large lakes fed by glaciers on the TP, it is difficult to monitor the modern process of transport and sedimentation because of the harsh environment. Consequently, it is very hard to understand how glacier-fed rivers influence the lakes.

Here we present a case study of glacier-fed Pumayum Co. This includes an analysis of grain size significance, spatial distribution and transport trend of surface sediments. We also study the hydrodynamics process and sources of clastic sediments, as well as the influence of the biggest inflow river on the clastic sedimentation. By comparing the time series of grain size of a short gravity core with observed temperature data from a meteorological station, the environmental significance of grain size is identified.

\section{Study area}

Pumayum Co (5030 $\mathrm{m}$ a.s.1.) is in a mountain basin in the pre-Himalayas of Tibet (Figure 1). It is a semi-closed lake, with surface area $290 \mathrm{~km}^{2}$ and catchment area $\sim 1233 \mathrm{~km}^{2}$. Mean annual temperature is $2-4^{\circ} \mathrm{C}$ [25]. According to data from 1976-1994 at Dui hydrologic station on the northeast lake shore, mean annual precipitation was $357 \mathrm{~mm}$, and mean annual evaporation of the lake surface reached $1770 \mathrm{~mm}$. Therefore, inflows are essential for maintaining lake water volume balance. The Jiaqu River, whose flow is from glacier meltwater south of the lake, is the largest inflow, accounting for $\sim 77 \%$ of the total. The distance from the headwaters to the lake is no more than $50 \mathrm{~km}$, so the river has a steep drop and strong current [26]. There is a subsurface alluvial fan of water depth $<4 \mathrm{~m}$ on the west side of the lake, which is mainly the result of sediment deposited by the Jiaqu River (Figure 1). There is a newly excavated open channel on the east side, through which water joins the Kadongjaqu River during high lake levels. The Kadongjaqu River flows into Yamzhoyum Co, which is about $40 \mathrm{~km}$ north of Pumayum Co. There are three small islands in this lake (Figure 1). This lake has a solid paleolimnologic [19,26-28] and limnologic [29-31] research history, supported by the likes of the National Natural Science Founda- tion of China.

\section{Materials and methods}

Eighty-four gravity sediment cores were collected (Figure 1(b)). All cores for this study were taken 1-2 cm from the surface. The upper $27 \mathrm{~cm}$ of a long core, PYG04, was sliced at $1 \mathrm{~cm}$ intervals. All sediments were measured by a Mastersizer 2000 laser-diffraction particle analyzer (Malvern). See $[32,33]$ for the measurement method.

GRADISTAT [34] software was used to calculate grain size parameters with Udden-Wentworth $\phi$ expression. The parameters of mean grain size $\left(\bar{x}_{\phi}\right)$, such as median grain size $\left(D_{50}(\phi)\right)$, sorting coefficient $\left(\sigma_{\phi}\right)$, and skewness $\left(S K_{\phi}\right)$, were calculated by the moment method. Surfer 8.0 software was used to construct isoline maps of the grain size parameters.

The upper $27 \mathrm{~cm}$ of core PYG04 was dated using the ${ }^{137} \mathrm{Cs}$ and ${ }^{210} \mathrm{~Pb}$ dating method at Nanjing Institute of Geography and Limnology, Chinese Academy of Sciences.

\section{Results and discussion}

\subsection{Main character and spatial distribution of grain size of surface sediments}

The Folk ternary diagram [35] from GRADISTAT software was used to name and classify the sediments. Lithologically, 70 surface sediments (excluding several coarse samples near shore) of Pumayum Co are silt and sandy silt, except several silty sand sediments.

Figure 2 shows the distribution of grain size parameters. The main grain size is $2.61-6.78 \phi$, averaging $5.64 \phi(20$ $\mu \mathrm{m})$, and medium grain size 2.2-6.98 $\phi$, averaging $5.68 \phi$ $(20 \mu \mathrm{m})$. Figures of main and medium grain size show that grain size decreases with increasing water depth. Although the correlation coefficient between the $\phi$ value of grain size and water depth is $0.348(\alpha=0.01)$, grain size does not show a circular distribution like an ideal lake. Most of the mean and medium grain sizes in this lake are 6-7 $\phi(8-30 \mu \mathrm{m})$, relatively coarse. The coarsest sediments $(<5 \phi$ or $>30 \mu \mathrm{m})$ are distributed on the subsurface alluvial fan, south and east shallow water areas, and areas around the three islands. The lake area near the north shore has deep water and small grain size. Relatively fine sediments are found at the fan front.

The $\sigma_{\phi}$ values are from 1.02-3.34, with an average of 1.69. Sorting of most sediments is poor (1-2), except very poor at the fan front (Figure 2).

The $S K_{\phi}$ values are from -1.12 to 2.18 , with an average of -0.21 . Most $S K_{\phi}$ are negative. Similar to $D_{50}(\phi), S K_{\phi}$ has positive (coarse) skewness $(>0.43)$ at the subsurface alluvial fan, negative (fine) skewness $(<-0.43)$ at the open lake area, 


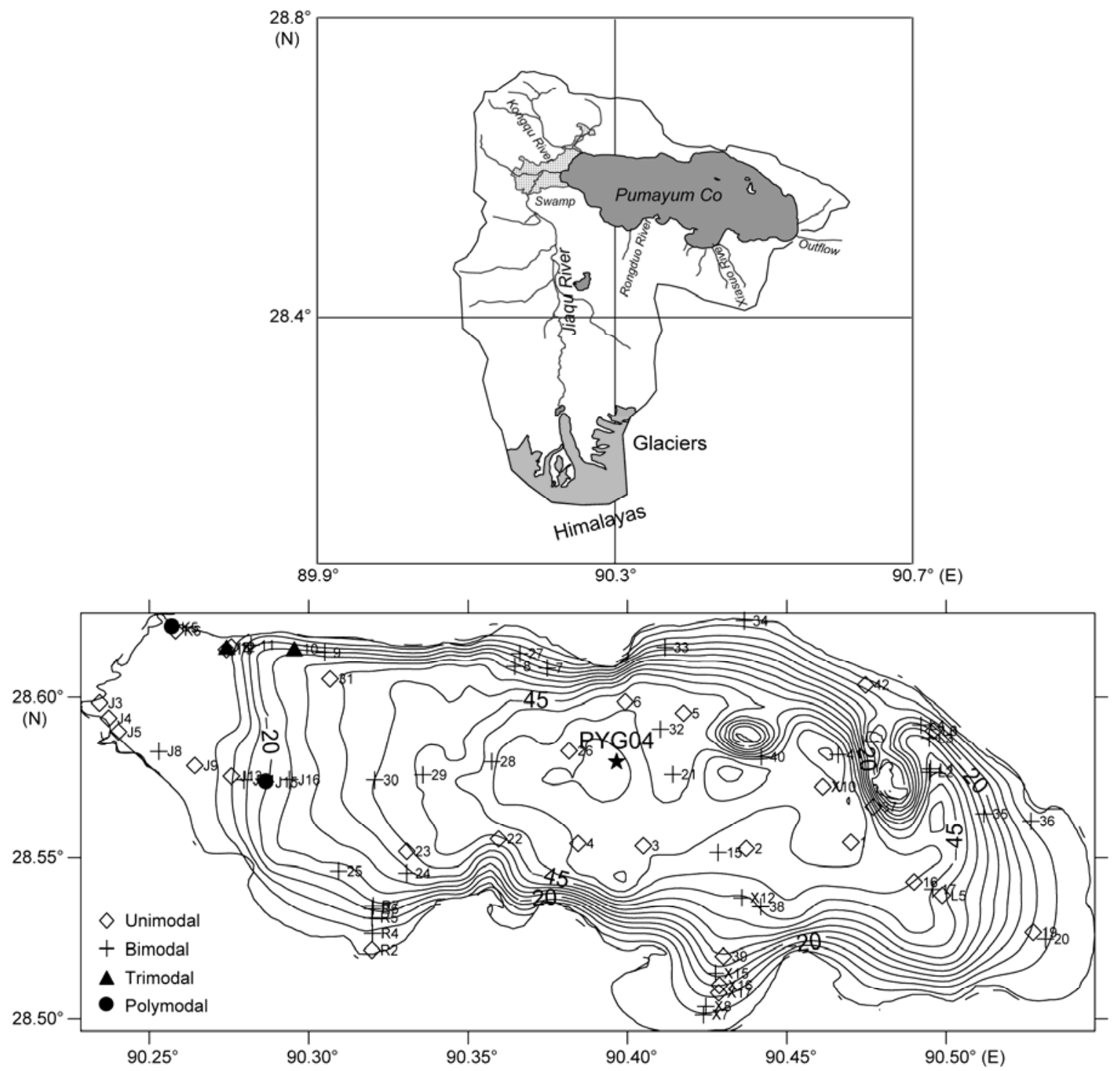

Figure 1 Location of Pumayum Co (a), and sampling site distribution (b). Curves are bathymetric (m). Numbers beside sampling sites are sample numbers.

and nearly symmetrical $(-0.43$ to 0.43$)$ at other lake areas.

The distributions of the grain size parameters show spatial variations at the open lake area, near-shore areas, and river mouth, indicating different hydrodynamic environments. The isolines have a north-south orientation, which may reflect the influence of the Jiaqu River.

The spatial distribution of sand, silt, and clay content also show a clear spatial variation of lake sediments (Figure $3(\mathrm{a})-(\mathrm{c}))$. The sediments in the open area consist mainly of silt, but also contain $10 \%-20 \%$ sand. The sand contents of the subsurface alluvial fan, shallow water area near the south and east shores, and lake area surrounding the islands are $>40 \%$. Clay components, occupying $0.5 \%$, are very low throughout the lake, but relatively high $(>1 \%)$ at the front of the subsurface alluvial fan and in the shallow water area near the south and east shores.

Significantly, grain size of lake sediment at the open lake area $\left(D_{50}(\phi), 5-7 \phi ;>8 \phi\right.$ clay content, $\left.<20 \%\right)$ is coarser than in humid-area lakes, such as those in the lower-middle reaches of the Yangtze River $\left(D_{50}(\phi), 6.5-8.7 \phi,>8 \phi\right.$ clay content, 25\%-65\%) and Lake Dianchi in Yunnan Province $\left(D_{50}(\phi), 9.6-11.5 \phi ;>8 \phi\right.$ clay content, $\left.81.6 \%-94.8 \%\right)$. The grain size is coarser than in temperate semi-humid areas, such as Lake Daihai $\left(D_{50}(\phi), 5-8 \phi ;>8 \phi\right.$ clay content, 20\%-53\%) and Lake Ulungur in Xinjiang [36]. Pumayum $\mathrm{Co}$ is in an alpine area at altitude greater than $5000 \mathrm{~m}$, characterized by a large diurnal temperature difference and strong physical weathering, which results in a coarse sediment source. The largest inflow with a steep drop and strong current looks like white glue, carrying many large particles (weight content of suspended particles is about $0.0182 \%)$. Because of this, a single subsurface alluvial fan developed to the west of the lake. Therefore, the silt and poor sorting characteristics of lake sediments in the open 

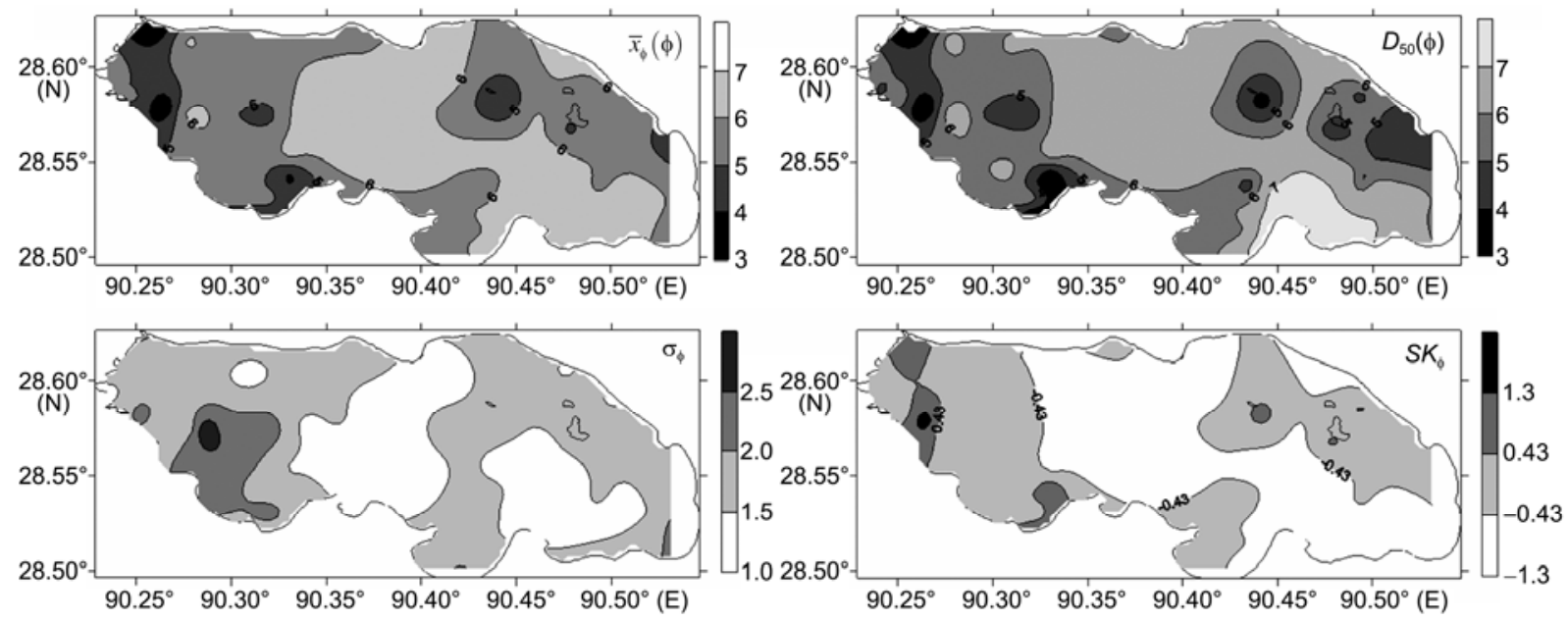

Figure 2 Distribution of grain size parameters of surface sediments in Pumayum Co.
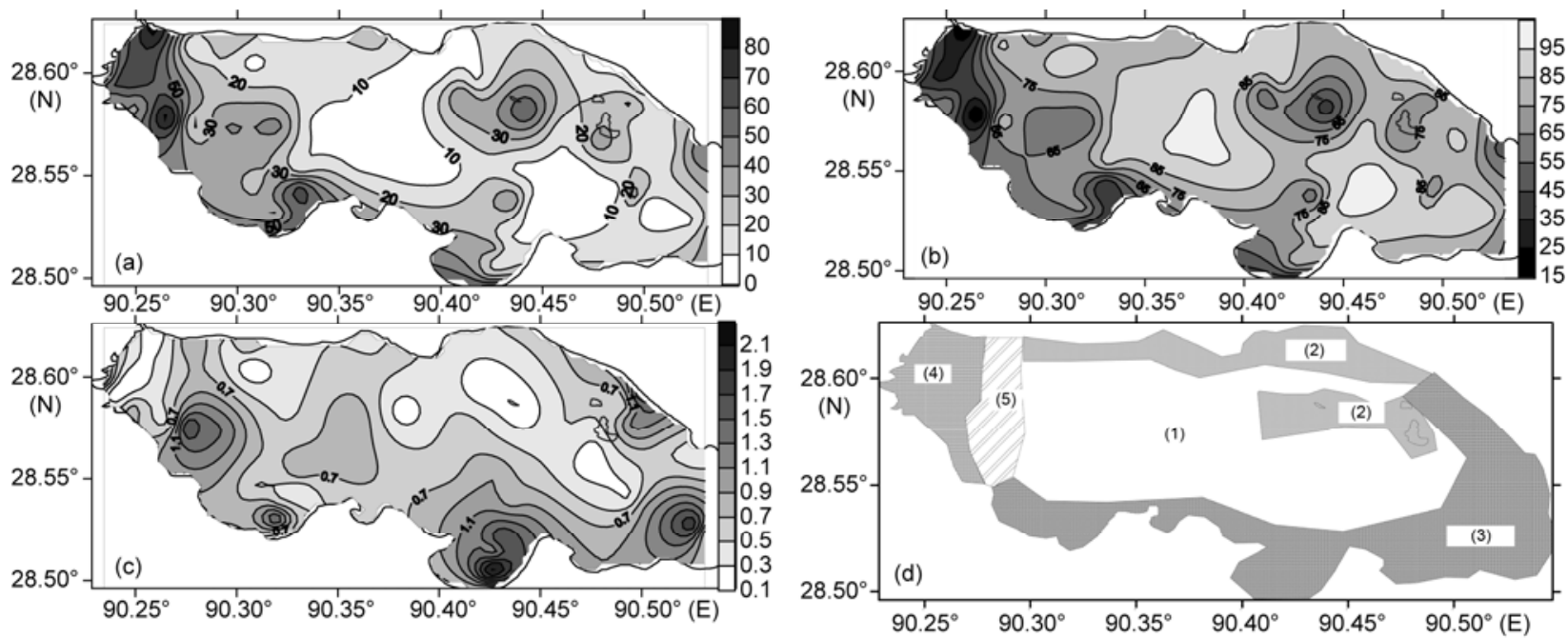

Figure 3 Percentage contents of sand (a), silt (b), and clay (c) in surface sediments, plus distribution of various clastic sedimentation (d) of Pumayum Co. Units of (a)-(c) are in \%. In (d), (1)-(5) respectively denote sedimentation of open lake area (offshore), inshore deep water, inshore shallow water, delta, and delta front (transition zone).

area reflect the alpine climate and supply to this lake.

The spatial variation of lake grain size indicates a difference of sedimentary model, resulting from different transport agents. To understand these different sedimentary models, it is necessary to analyze the transport agents within different lake areas. The frequency distribution curves of grain size can be used to compare and determine the spatial difference of these transport agents.

\subsection{Analysis of grain size frequency distribution curves}

Figure 4 shows that for 70 samples, 37 have a bimodal grain size distribution, and 26 unimodal. According to characteristics of the grain size frequency distribution curves, as well as spatial variations of parameters and components of grain size in different lake areas, sedimentation types (sedimen- tary models) can be described as follows (Figure 3(d))

Open lake area (offshore) sedimentation. Figure 4(a) and (b) shows the frequency distribution curves. The boundary is similar to the $7 \phi$ isoline of $\bar{x}_{\phi}(\phi)$, excluding the north and south inshore areas. It is characterized by a unimodal distribution and the same shape (Figure 4(a)). The mode is from $6.8-7.3 \phi(9-6 \mu \mathrm{m})$, tailing at the coarse end. This unified grain size distribution and silty mode indicates that the main transport agent in the open lake area is suspended load transport $[37,38]$. However, there are some samples with bimodal distributions (Figure 4(b)), characterized by a small, coarse grain peak in addition to the main fine peak. Analysis of this is given in the next sedimentation type.

Inshore deep-water sedimentation. Figure 4(c) and (h) shows the frequency distribution curves. These are in the deep-water area around the three small islands and north 

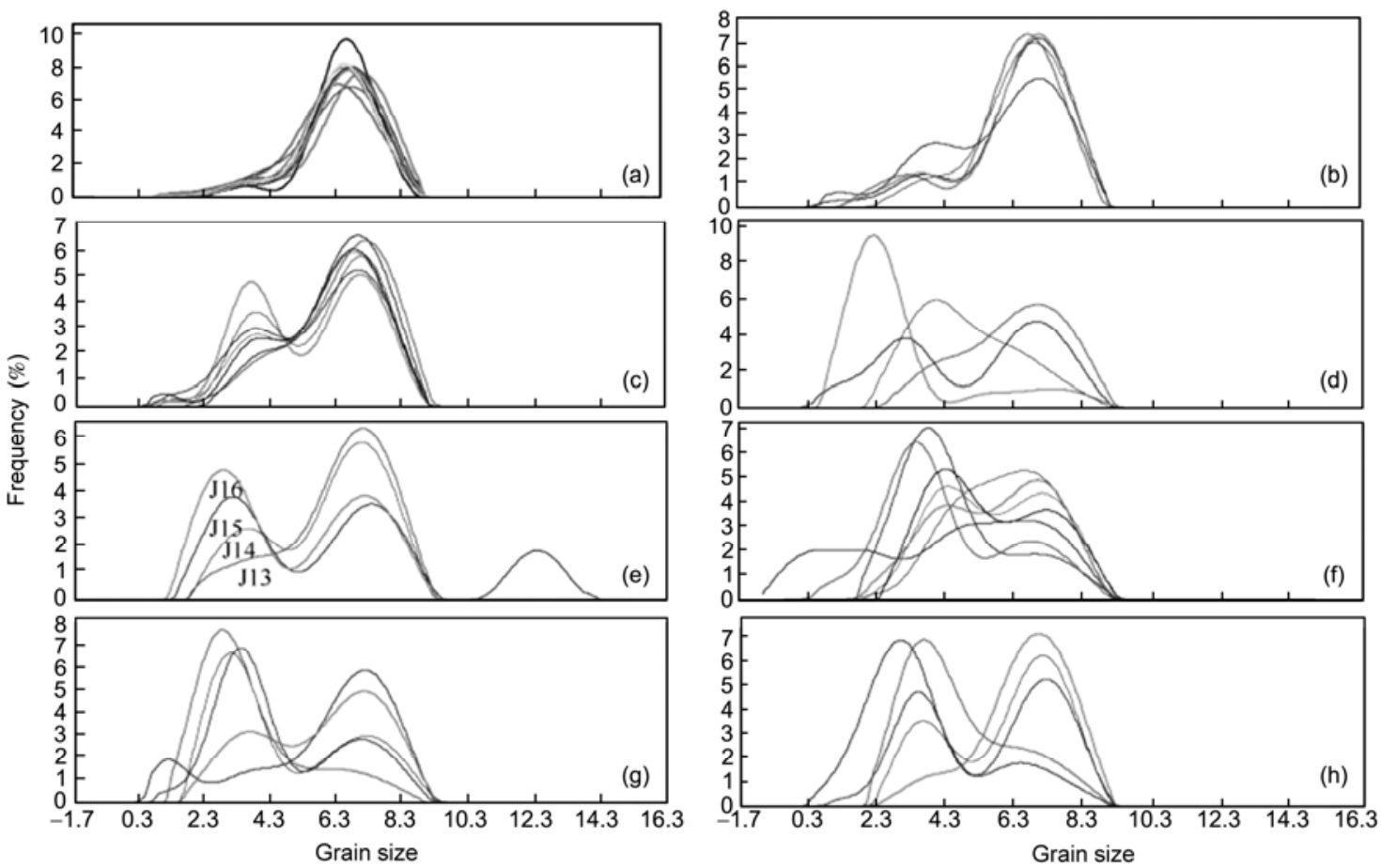

Figure 4 Frequency distribution curves of grain size of surface sediments in different parts of Pumayum Co. (a) Unimodal in open lake area (samples 1-6, 22, 23, 26, X10); (b) bimodal in open lake area (samples 15, 28-30, 32); (c) bimodal in north inshore area (samples 7-9, 27, 33, 34); (d) delta area; (e) delta front area; (f) east inshore area (samples L1-L4, 19, 35, 36); (g) Rongduo bay (samples R2, R4-R7); (h) around the islands (samples 21, 32, 37, 40, 41).

inshore area. Most curves are bimodal, similar to the bimodal samples in the open area, i.e. there is a coarse grain peak at $3.8 \phi(72 \mu \mathrm{m})$ and fine peak with the mode 6.8-7.3 $\phi$. The difference is a higher coarse component and higher coarse peak. The bimodal distribution indicates different sources transported by different agents. The lake environment at water depth $>20 \mathrm{~m}$ is stable and has lower energy, because the wave base is shallow [39]. Therefore, sediments under this deep water are hardly disturbed by waves. In Pumayum Co, water depths of the open area and north area are more than $35 \mathrm{~m}$; the area near the three islands is deeper than $50 \mathrm{~m}$ but has coarser sediments. The closer to the islands the sample is, the larger the grain size with higher peak. Therefore, it is difficult to explain the source of the coarse sediment component by lake waves. One possibility is that terrigenous coarse sediments were transported by seasonal streams, slope afflux or eolian transport.

Inshore shallow water sedimentation. Most of the sample curves at the east and south inshore lake areas have a bimodal distribution (Figure 4(f), (g)). The main peak of grain size distribution for samples closer to shore is at the coarser end, reflecting the high energy environment caused by lake waves. The main peak shifts toward the fine end for samples farther from the lakeshore, because of weaker waves and stronger suspended load transport.

Delta sedimentation. Most of the lithology of sediments at the subsurface alluvial fan (delta) is coarse silt or fine sand. Water depth on the delta is less than $4 \mathrm{~m}$. Figure 4(d) shows a sedimentary environment with high energy, unimodal with 2.3-4 $\phi(203-63 \mu \mathrm{m})$ mode or bimodal with the main peak at the coarse end. Compared to the ocean, the hydrodynamics of a lake are weaker and sediments are primarily transported by fluvial force. The curves do not vary regularly with distance of the sample to the west shore, indicating that the sampling section may not be along the stream thread of the Jiaqu River.

Delta front sedimentation (transition zone). From the delta front to central lake (J13-J16, Figure 4(e)), the coarser grain peak increases gradually as the finer grain peak declines. Combined with the characteristics of higher clay content and poorer sorting, this area is assumed a transition zone where sand sorting and transport cease [40]. This may indicate that influences of the river and lake cancel out at sample J13. Toward the central lake, however, the influence of the river decreases and that of lake waves increases. This is reflected by increase of the coarse end peak, until sample J16 at water depth $24 \mathrm{~m}$. The gradual overlap of clay content at the delta front also shows the sedimentary particularity of this area.

The discussion above cannot explain the relatively high clay content of the south and east inshore sediments. This may result from incomplete removal of endogenous carbonate. There is greater than half-content of biogenous carbonate in these shallow-water area samples [31]. One of the per-treatment processes in grain size analysis is the removal of organic matter from samples. During this process, the 
beaker fills with big bubbles, carrying carbonate attached to the beaker. Therefore, the amount of carbonate cannot be eliminated by acid and may be detected by the particle analyzer, which may cause the relative high clay content.

\subsection{Sediment transport direction analysis using GSTA}

The analysis above demonstrates that the sediment process is influenced by several transport agents. Given these agents, we wish to know the direction of sediment transport. This is important to understanding the sedimentary environment of this lake. The grain size character of sediments can specify the sediment transport direction. Mclaren et al. [41] and Mclaren and Bowles [42] concluded that successive deposits along the transport path must either become more sorted, finer and more negatively skewed, or become more sorted, coarser and more positively skewed. Gao and Collins [43] modified this hypothesis and developed net sediment transport patterns-Grain Size Trend Analysis (GSTA), which has been applied in multiple marine environments [44-49].

GSTA is a sediment dynamics model. The procedures for determining trends include the following three steps [50,51]. First, grain size parameters at each sampling station are compared with those of the neighboring stations to find all trend vectors. To identify a neighboring station, a characteristic distance $D C$ is specified. If the distance between any two stations is less than $D C$, they are considered neighboring stations and their grain-size parameters are compared. Second, the trend vectors are summed to produce a single vector $\boldsymbol{R}(x, y)$. Third, a filtering operation is done to reduce any remaining noise. The residual vectors form a general pattern representing a net sediment transport pathway.

A regular and uniform sampling grid is necessary for GSTA [50], but it is difficult to sample like this. To overcome this problem, equidistant Kriging interpolation between existing samples is used within Surfer 8.0 (Golden Software). The interpolation distance is $0.012^{\circ}$. Based on the importance of $D C$, normally different $D C$ values are used to compare simulation effects. Figure 5 illustrates net transport trends with $D C=1^{\prime}, 2^{\prime}, 3^{\prime}, 4^{\prime}, 5^{\prime}, 6^{\prime}$. The general transport trend of Pumayum Co is from west to east. The trends are relatively sensitive to $D C$, in contrast to results from Lake Yuehu [52]. This discrepancy may result from a different sampling density.

The design of sampling sites is crucial for GSTA accuracy. In the open lake area, sampling sites are comparatively uniform, and therefore GSTA results should reflect the inherent net transport direction. In other areas, because of reduced or nonuniform sampling density, GSTA results are questionable.

In the open area, the westerly net transport direction shows that there is no depocenter in this lake as in Lake
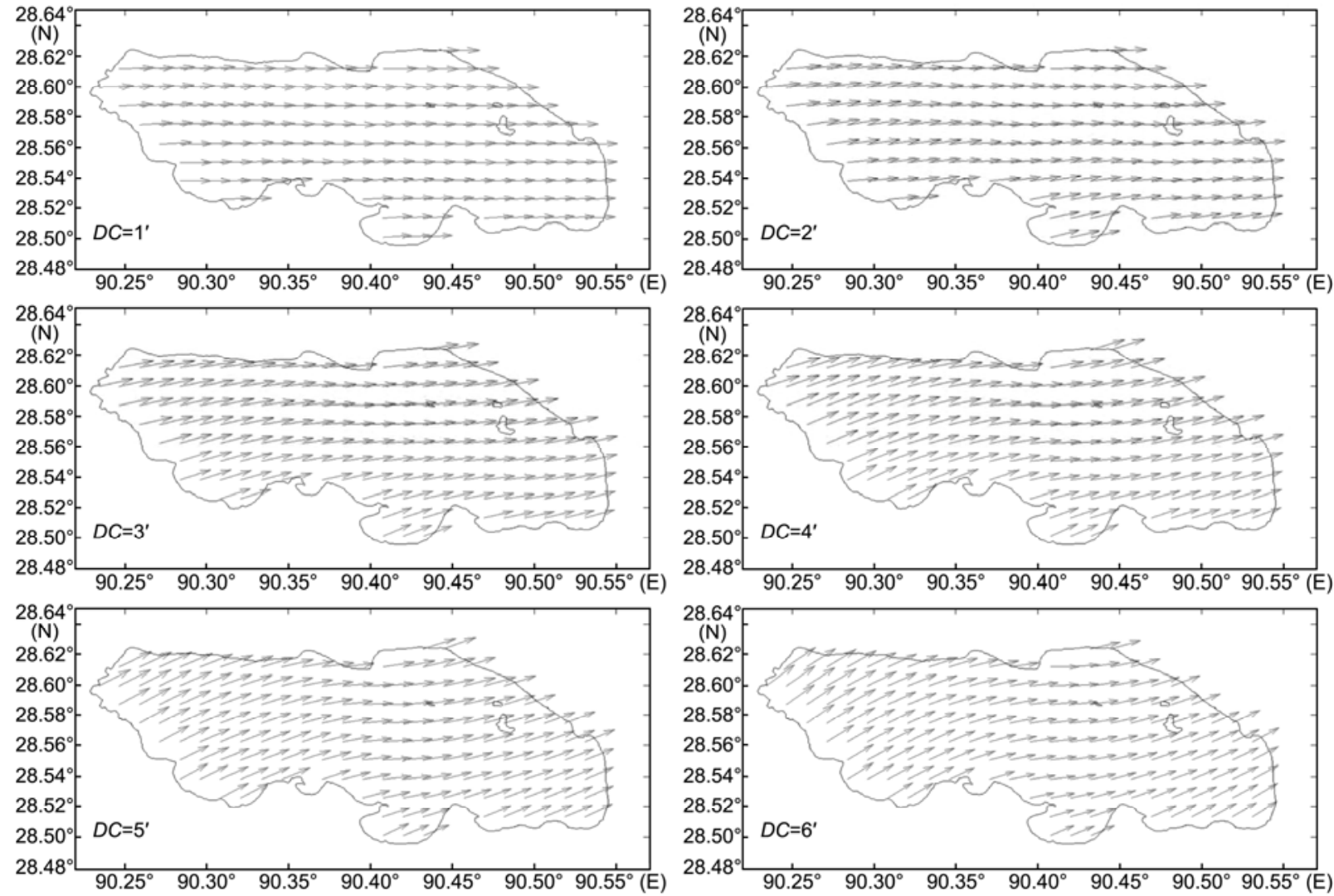

Figure 5 Results of GSTA using different $D C$. 
Yuehu. This accords with a non-semicircular distribution of grain size parameters, reflecting the dominant influence of the largest inflow, the Jiaqu River (accounting for $77 \%$ of the total inflow). Pumayum Co is a semi-enclosed lake with outflow on the east bank, through which lake water can flow out during periods of high lake level. Its instantaneous flow equals the sum of all inflows. Therefore, the trend from west to east is credible.

\subsection{Environmental significance of grain size-reliability of the method discriminating the hydrodynamic process}

Figure 6 compares time series of sediment grain size parameters in Pumayum Co with temperature change observed at Nagarzê Zong meteorological station. The sedimentation rate of the core top is $0.25 \mathrm{~cm} / \mathrm{a}(4 \mathrm{a} / \mathrm{cm})$. Therefore, for comparison, temperature values are 4 a moving averages.

Grain size frequency distribution curves of the 27 samples are unimodal, with 6.8-7.3 $\phi$ mode. The coarse trailers are not obvious, indicating they are suspended loads. Sorting values increase (become poor) with grain size, in accord with sand content change (Figure 6).

Nine of the 27 samples are within the range of observation data. The variations of grain size and LKZ-T show great consistency-grain size increases and sorting becomes poor with temperature increase, and vice versa. In general, grain size indicates lake water depth indirectly. That is, the deeper the water, the farther from the shore the sampling site, and the smaller the depositing dynamic. However, Pumayum Co is semi-enclosed, with glacier meltwater an important supply. The coarser sediments suggest a stronger dynamic. Because of the strong effect of glacier meltwater supply on the west bank, the general transport trend is from west to east. Consequently, combining results of the modern sedimentary process analysis, our reasoning is as follows: with increasing temperature, glacier meltwater increases, carrying coarser particles and making the sorting poorer. Therefore, the grain size of this lake sediment serves as a good indicator of local temperature on short time scales.

\section{Conclusions}

The characteristics of sediment grain size in Pumayum Co are controlled by weather and runoff conditions. Grain size has a distinct alpine, semi-arid character, with larger sizes, poor sorting, and low clay content. There are five clastic sedimentation types (sedimentary models) in the lake: open lake area (offshore), inshore deep-water, inshore shallow water, delta, and delta front (transition zone). Grain size characteristics in open-area sediments reveal that suspended load transport is the main transport agent. The west-east transport trend revealed by GSTA simulation indicates the discharge lake character. GSTA and the sedimentary model discrimination can reveal the lake dynamic process. The conclusions inform climate reconstruction, using grain size of a lake sediment core.

(1) On short time scales, grain size is a good indicator of local temperature. The influences of the Jiaqu River on the lake must be taken into account when reconstructing the paleoclimate using a lake sediment core. The transport trend from west to east also indicates that the influence of the Jiaqu River cannot be confined to the subsurface fan. Further, as a river fed by glacial meltwater, the Jiaqu flow is controlled by temperature.

(2) Errors will result if only the mean or median grain

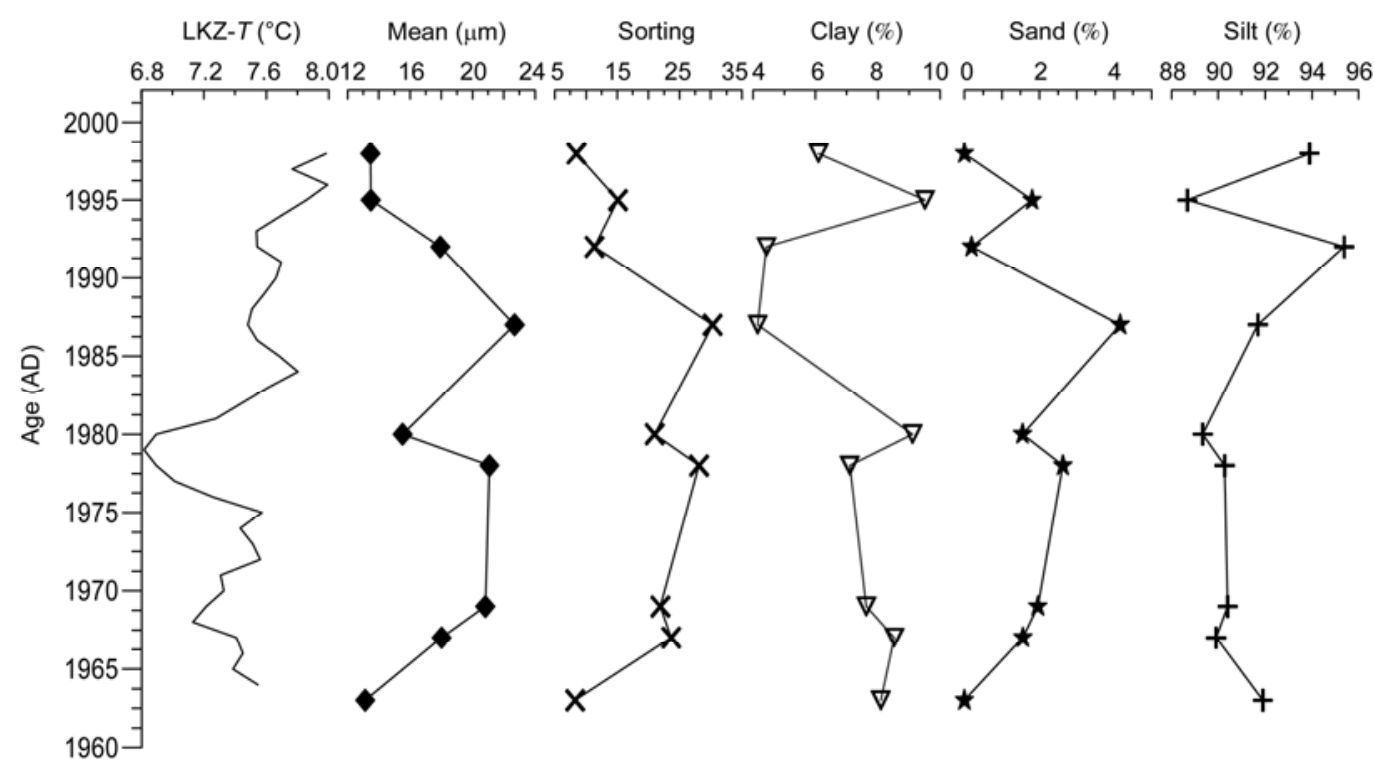

Figure 6 Comparison of vertical change of grain size parameters with observed temperature. LKZ-T is observed annual average temperature change. Mean is mean grain size, in $\mu \mathrm{m}$. Sorting is sorting coefficient, calculated by moment arithmetic method. 
size are used to construct paleoclimate. The main transport agent may vary with time, because of the complex deposition environment. The mean or median grain sizes only reflect the magnitude of transport agent, but cannot distinguish its type. The frequency distribution curve of grain size may compensate for this. In fact, some researchers have succeeded in reconstructing the paleoenvironment of Lake Daihai [38] by partitioning the grain size component, thereby recovering the dynamic history at great length [37,53]. This will be our future target.

From this case study, we found that the sedimentation model GSTA and deposition sedimentary model discrimination can be used to illustrate the glacier-fed lake dynamic process on the TP. It would be helpful to identify the clastic source of core sediment and dominant factors, as well as the influence distance of inflow rivers. This would lead to better paleoclimatic reconstruction for this type of lake.

We thank two anonymous reviewers for their valuable comments. This work was supported by the National Natural Science Foundation of China (41130529, 41101181 and 41102117) and the Knowledge Innovation Key Program of the Chinese Academy of Sciences (KZCX2-EW-113 and $K Z C X 2-Y W-146)$.

1 Yao T D. Glacial fluctuations and its impacts on lakes in the southern Tibetan Plateau. Chin Sci Bull, 2010, 55: 2071

2 Liu X D, Chen B D. Climatic warming in the Tibetan Plateau during recent decades. Int J Climatol, 2000, 20: 1729-1742

3 Thompson L G, Mosley-Thompson E, Davis J F, et al. Holocene-Late Pleistocene climatic ice core records from Qinghai-Tibetan Plateau. Science, 1989, 246: 474-477

4 Thompson L G, Davis J F. "Recent warming": Ice core evidence from tropical ice core with emphasis on central Asia. Global Planet Change, 1993, 7: 145-156

5 Thompson L G, Yao T, Davis J F, et al. Tropical climate instability: The last glacial cycle from a Qinghai-Tibetan ice core. Science, 1997, 276: 1821-1825

6 Thompson L G, Yao T, Mosley-Thompson E, et al. A high-resolution millennial record of the South Asian Monsoon from Himalayan ice cores. Science, 2000, 289: 1916-1919

7 Wang L H, Lu A X, Yao T D, et al. The study of typical glaciers and lakes fluctuations using remote sensing in Qinghai-Tibetan Plateau. In: Geoscience and Remote Sensing Symposium, 2007. IGARSS 2007. IEEE Int, 4526-4529

8 Bian D, Bian B, La B, et al. The response of water level of Selin Co to climate change during 1975-2008 (in Chinese). Acta Geogr Sin, 2010, 65: 313-319

9 Wan W, Xiao P F, Feng X Z, et al. Remote sensing analysis for changes of lakes in the southeast of Qiangtang area, Qinghai-Tibet Plateau in recent 30 years (in Chinese). J Lake Sci, 2010, 22: 874-881

10 Wu Y H, Zhu L P, Ye Q H, et al. The response of lake-glacier variations to climate change in Nam Co Catchment, central Tibetan Plateau, during 1970-2000. J Geogr Sci, 2008, 18: 177-189

11 Zhu L P, Xie M P, Wu Y H. Quantitative analysis of lake area variations and the influence factors from 1971 to 2004 in the Nam Co basin of the Tibetan Plateau. Chin Sci Bull, 2010, 55: 1294-1303

12 Ye Q H, Yao T D, Chen F, et al. Change in Mapam Yumco basin on Tibetan Plateau during 1974-2003. J China Univ Geosci, 2008, 19: 135-145

13 Chen J A, Wan G J, Zhang F, et al. Environmental records of lacustrine sediments in different time scales: Sediment grain size as an example. Sci China Ser D-Earth Sci, 2004, 47: 954-960

14 Chen F H, Huang X Z, Zhang J W, et al. Humid Little Ice Age in arid central Asia documented by Bosten Lake, Xinjiang, China. Sci China Ser D-Earth Sci, 2006, 49: 1280-1290

15 Zhang J W, Chen F H, Battarbee R, et al. High-resolution precipitation variations in the North Tibet Plateau over the last 800 years documented by sediment cores of Lake Qinghai. Chin Sci Bull, 2003, 48: $1451-1456$

16 Peng Y J, Xiao J L, Nakamura T, et al. Holocene East Asian monsoonal precipitation pattern revealed by grain-size distribution of core sediments of Daihai Lake in Inner Mongolia of north-central China. Earth Planet Sci Lett, 2005, 233: 467-479

17 Wang J B, Zhu L P. Grain-size characteristics and their paleo-environmental significance of Chen Co Lake sediments in southern Tibet (in Chinese). Prog Geogr, 2002, 21: 58-66

18 Zhu L P, Zhen X L, Wang J B, et al. A 30000-year record of environmental changes inferred from Lake Chen Co, Southern Tibet. J Paleolimnol, 2009, 42: 343-358

19 Wang J B, Zhu L P, Nishimura M, et al. Spatial variability and correlation of environmental proxies during the past 18000 years among multiple cores from Lake Pumoyum Co, Tibet, China. J Paleolimnol, 2009, 42: 303-315

20 Mügler L, Gleixner G, Günther F, et al. A multi-proxy approach to reconstruct hydrological changes and Holocene climate development of Nam Co, Central Tibet. J Paleolimnol, 2010, 43: 625-648

21 Wu Y H, Lücke A, Jin Z D, et al. Holocene climate development on the central Tibetan Plateau: A sedimentary record from Cuoe Lake. Palaeogeogr Palaeoclimatol Palaeoecol, 2006, 234: 328-340

22 Morrill C. The influence of Asian summer monsoon variability on the water balance of a Tibetan lake. J Paleolimnol, 2004, 32: 273-286

23 Dean. Recent advances in global lake coring hold promise for global change research in paleolimnology. J Paleolimnol, 2010, 44: 741-743

24 Henderso A G, Holmes J A. Palaeolimnological evidence for environmental change over the past millennium from Lake Qinghai sediments: A review and future research prospective. Quat Int, 2009, 194: 134-147

25 Wang S M, Dou H S. Chinese Lake Catalogue (in Chinese). Beijing: Science Press, 1998

26 Zhu L P, Ju J T, Wang J B, et al. Environmental changes recorded in core sediments from the Pumoyum Co Lake of the Tibetan Plateau during the initial stage of the last deglacial period (in Chinese). Quart Sci, 2006, 26: 772-780

27 Wang J B, Zhu L P, Ju J T, et al. Environmental changes reflected by a comparative proxy study among multiple cores from Pumoyum Co, Tibet in the last 200 years (in Chinese). J Lake Sci, 2009, 21: 819826

28 Lü X M, Zhu L P, Nishimura M, et al. A high-resolution environmental change record since 19 cal ka BP in Pumoyum Co, southern Tibet. Chin Sci Bull, 2011, 56: 2931-2940

29 Zhu L P, Ju J T, Wang Y, et al. Composition, spatial distribution, and environmental significance of water ions in Pumayum Co catchment, southern Tibet. J Geogr Sci, 2010, 20: 109-120

30 Zhu L P, Ju J T, Wang J B, et al. Further discussion about the features of Lake Puma Yum Co, South Tibet, China. Limnology, 2010, 11: $281-287$

31 Ju J T, Zhu L P, Wang J B, et al. Water and sediment chemistry of Lake Pumayum Co, South Tibet, China: Implications for interpreting sediment carbonate. J Paleolimnol, 2010, 43: 463-474

32 Wang J B, Zhu L P. Influence of different pre-treatments on grainsize measurement of lake sediments (in Chinese). J Lake Sci, 2005, 17: 17-23

33 Wang J B, Ju J T, Zhu L P. Comparison of lake sediment grain size results measured by two laser diffraction particle size analyzers (in Chinese). J Lake Sci, 2007, 19: 509-515

34 Blott S J, Pye K. GRADISTAT: A grain size distribution and statistics package for the analysis of unconsolidated sediments. Earth Surf Proc Landf, 2001, 26: 1237-1248

35 Folk R L. Petrology of Sedimentary Rocks. 2nd ed. Austin: Hemphill Publishing Co, 1980 
36 Wang S M, et al. The Dauhai Lake: Environment Evolution and Climate Change (in Chinese). Hefei: China Science and Technology University Press, 1990

37 Yin Z Q, Qin X G, Wu J S, et al. Multimodal grain-size distribution characteristics and formation mechanism of lake sediments (in Chinese). Quart Sci, 2008, 28: 345-353

38 Xiao J L, Chang Z G, Si B, et al. Partitioning of the grain-size components of Dali Lake core sediments: Evidence for lake-level changes during the Holocene. J Paleolimnol, 2009, 42: 249-260

39 Ren M D, Wang N L. Introduction to Modern Depositional Environment (in Chinese). Beijing: Science Press, 1981. 61

40 Sly P G. Sedimentary processes in lakes. In: Lerman A, ed. Lakes: Chemistry, Geology, Physics. New York: Springer-Verlag, 1978

41 Mclaren P. An interpretation of trends in grain size measurements. J Sediment Petrol, 1981, 51: 611-624

42 McLaren P, Boeles D. The effects of sediment transport on grain-size distributions. J Sediment Petrol, 1985, 55: 457-470

43 Gao S, Collins M. Critique of the "McLaren Method" for defining sediment transpor paths. J Sediment Petrol, 1991, 61: 143-146

44 Gao S, Collins M. Net sediment transport patterns inferred from grain-size trends, based upon definition of "transport vectors". Sediment Geol, 1992, 80: 47-60

45 Gao S, Collins M. Anaysis of Grain Size trends, for defining sedi- ment transport pathways in marine environments. J Coast Res, 1994, 10: 70-78

46 Gao S, Collins M. Net sediment transport patterns inferred from grain-size trends. based upon definition of "transport Vectors"-reply. Sediment Geol, 1994, 90: 157-159

47 Shi X F, Chen C F, Liu Y G, et al. Trend analysis of sediment grain size and sedimentary process in the central South Yellow Sea. Chin Sci Bull, 2002, 47: 1202-1207

48 Duman M, Avc M, Duman S, et al. Surficial sediment distribution and net sediment transportpattern in IzmirBay, western Turkey. Continent Shelf Res, 2004, 24: 965-981

49 Gao S. Grain Size Trend Analysis: Principle and applicability (in Chinese). Acta Sedimentol Sin, 2009, 27: 826-836

50 Gao S, Collins. The use of grain size trends in marine sediment dynamics (in Chinese). Bull Nat Sci Found Chin, 1998, 4: 241-246

51 Gao S. A fortran program for grain-size trend analysis to define net sediment transport pathways. Comput Geosci, 1996, 22: 449-452

52 Jia J J, Cheng P, Gao S. Comparison between grain size trends derived from irregular and regular sampling grids with the help of GIS interpolation tools (in Chinese). Mar Geol Quat Geol, 2004, 24: 135-141

53 Qin X G, Cai B G, Liu T S. Loess record of the aerodynamic environment in the East Asia monsoon area since 60000 years before present. J Geophys Res, 2005, 110: B01204

Open Access This article is distributed under the terms of the Creative Commons Attribution License which permits any use, distribution, and reproduction in any medium, provided the original author(s) and source are credited. 